\title{
El Proyecto Mujeres Maestras del Perú. Estudio de caso sobre identidades docentes ${ }^{*}$
}

\author{
RICARD HUERTA RAMÓN** \\ Universitat de València - España
}

Recibido el 05-12-2016; primera evaluación el 10-04-2017; segunda evaluación el 17-04-2017; tercera evaluación el 10-08-2017; aceptado el 23-11-2017

\section{RESUMEN}

El proyecto «Mujeres Maestras de Perú» nos acerca a las opiniones de veintiun maestras peruanas. Las que trabajan en entornos menos favorecidos e insisten en su precocidad vocacional. Las maestras nos hablan de dicho factor vocacional como de algo que ya aparece en su infancia en tanto que deseo explícito de dedicarse a la docencia. Nuestra investigación parte de un enfoque cualitativo, mediante un estudio de caso al que incorporamos elementos de rango artístico (Investigación basada en las artes). Utilizamos grabaciones audiovisuales como instrumento de recogida de datos. Desde la educación artística, visibilizamos las identidades del colectivo docente como homenaje y reivindicación profesional. De las narrativas personales de mujeres de diversos estratos sociales, edades y situaciones particulares, recogidas a partir de entrevistas, surgen sus intereses y preocupaciones.

Palabras clave: mujeres, educación artística, cultura visual, estudio de caso, maestras, identidad.

\footnotetext{
La investigación forma parte del Proyecto de Innovación Educativa «Second Round: Recursos per impulsar l'Educació Artística» (UV-SFPIE_GER15-313435), generado por el grupo CREARI de Investigación en Pedagogías Culturales (GIUV2013-103) del Instituto de Creatividad e Innovaciones Educativas de la Universitat de València (España).

** Profesor de educación artística en la Universitat de València (España). Investigador del Instituto Universitario de Creatividad e Innovaciones Educativas. Director de la publicación EARI Educación Artística Revista de Investigación, y del Diploma de Posgrado Educación Artística y Gestión de Museos. Doctor en Bellas Artes y licenciado en Música, Bellas Artes y Comunicación Audiovisual. Coordinador del Grupo CREARI de Investigación en Pedagogías Culturales (GIUV2013-103). Profesor del Departamento de Didáctica de la Expresión Musical, Plástica y Corporal de la Facultat de Magisteri. Contacto: ricard.huerta@uv.es
} 


\section{The Mujeres Maestras del Perú project. Case study on teaching identities}

\section{Abstract}

When discussing the professional aspects of the work of women teachers, it is usual to include the vocational factor as a main element. The question of vocational education incorporated progressively in the training period progresses. Teachers themselves talk about this as something that already appears in their childhood as an explicit desire to dedicate to teaching. With the project «Peruvian Women Teacher's» we approach the opinions on this and other issues. The process of preparation of the project in Lima initiated includes interviews with twenty-one women. Most teachers insist on their vocational precocity, especially those who working in poverty environments. We use case studies incorporating video through Arts Based Research. Art Education try to make visible the identities of the female teaching group. It is a tribute, but also a professional claim. Participants are teachers of different ages and particular situations. We have again verified that the vocational component is present in personal narratives.

Keywords: women, art education, visual culture, case studies, teachers, identity.

\section{O projeto Mujeres Maestras del Perú. Estudo de caso sobre identidades de ensino}

\section{Resumo}

Quando surge a questão do trabalho de professores é comum falar do factor profissional como elemento de primeira ordem. Os professores dizem-nos do seu vocação como algo que já aparece na infância, como um desejo explícito de dedicar-se ão ensino. Com o projeto "Mulheres Professores do Peru» nos aproximamos os pontos de vista dos professores em esta e outras questóes. Foi entrevistado vinte e um professores. A maioria deles insistem em sua precocidade profissional, especialmente aqueles que trabalham em ambientes desfavorecidos. Nossa pesquisa é qualitativa, use Pesquisa Baseada em Arts e estudo de caso. Educação artística deve tentar visíveis as questôes de identidade do corpo docente. Este é um tributo, mas também uma reivindicação profissional. Ao realizar a coleta de dados no Peru, visitei várias escolas em Lima. Foram entrevistadas mulheres de diferentes origens sociais, idades e situações diversas. $\mathrm{O}$ viés profissional é muito presente em suas narrativas pessoais.

Palavras-chave: mulheres, arte-educação, cultura visual, estudo de caso, professores, identidade. 


\section{INTRODUCCIÓN}

La mayoría de profesionales que se dedican a la educación infantil y primaria son mujeres. Esto sucede en los países iberoamericanos donde se viene desarrollando el proyecto Mujeres Maestras. Nuestra intención consiste en hacer visible esta realidad, recorriendo, para ello, a construir y difundir una imagen del colectivo que parte de tres miradas: la del artista, la del alumnado y la de las propias maestras. En este sentido la vertiente visual recoge numerosas cuestiones a valorar, como, por ejemplo, la propia «imagen» de las maestras: cómo las vemos, cómo se ven, cómo les gustaría ser vistas. En 2005, se inició el proyecto y desde entonces hemos realizado exposiciones y acciones en Chile, Uruguay, Argentina, Cuba, España, y en la sede del Parlamento Europeo de Bruselas. En 2017, se realizó una exposición en Perú.

Entre los objetivos del Proyecto Mujeres Maestras, podríamos destacar la intención de (a) potenciar la educación artística, reivindicando una mayor sensibilidad por parte de las instancias políticas y sociales; (b) reflexionar sobre las identidades docentes mediante un espíritu creativo, con deriva social y adecuado a los nuevos ritmos artísticos; (c) investigar sobre los factores positivos que pueden influir en una mejora del papel de la educación artística; (d) fomentar acciones colaborativas entre equipos de trabajo para animar el espacio formativo generando retos de futuro; (e) visibilizar la problemática de las mujeres que se dedican a la enseñanza y favorecer la transmisión de intereses entre colectivos. Además de esto, el proceso de reflexión nos lleva a mirar hacia el futuro incorporando temáticas como el papel de la conciliación familiar y laboral de las mujeres que trabajan (Alonso-Sanz, 2016). El retrato de cada maestra se construye a partir de su nombre o de alguna parte de este.
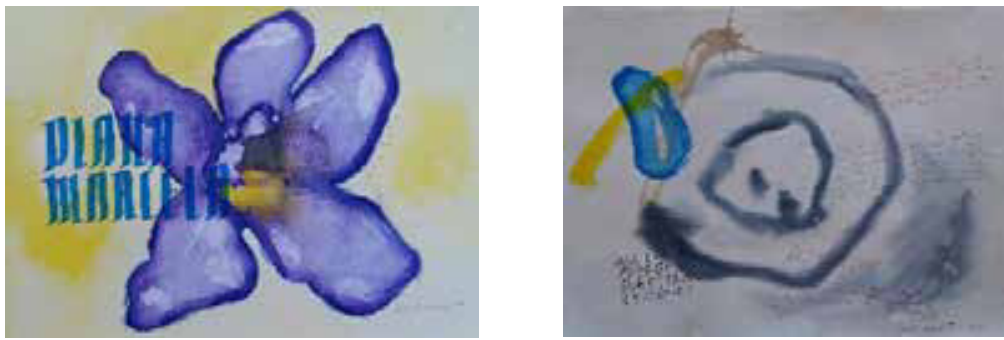

Figuras 1 y 2. Representaciones en pinturas de maestras de las series de Colombia (Diana Marcela) y de Uruguay (Ana Laura Cebrero).

Mujeres Maestras transita por los lugares de las docentes mediante sus narrativas personales, a través de sus vivencias y opiniones. Primero estable- 
cemos un diálogo con ellas, y luego trasladamos al museo la temática de las identidades, estableciendo así un diálogo creativo entre la escuela y museo. Nuestra observación y el posterior diseño artístico se basan en la mirada del observador atento, auscultando pacientemente desde la experiencia de quien indaga en sus propias inquietudes. En las entrevistas establecemos un criterio de elección que consiste en integrar el máximo de situaciones distintas. Hablamos con personas que representen a los diversos estamentos sociales y económicos, lo cual garantiza y refuerza la amplitud de miras del conjunto de participantes del estudio.

Nos hablan maestras de lugares distantes como la Institución Educativa Parroquial de Acción Conjunta Corazón de Jesús (Jicamarca, San Juan de Lurigancho), la Institución Educativa Parroquial Nuestra Señora de la Luz (San Isidro, Lima), o la Asociación Educativa Colegio Caritas Graciosas (Miraflores, Lima). Además, tenemos en cuenta el factor edad y experiencia en las aulas, utilizando relatos de maestras muy jóvenes y de profesionales con dilatada experiencia. Intentamos acercar las artes y la educación artística a las actividades que propician encuentros entre docentes, escuelas y museos (Huerta, 2009). Con estas acciones artísticas, ponemos en evidencia las realidades en las cuales nos movemos, aportando, así, ideas para mejorar nuestras formas de educar. Al acercar las artes al terreno educativo, promovemos una educación estética y crítica (Huerta, 2016), compartiendo la preocupación por cohesionar las diversas opciones que presenta la educación artística en el espectro iberoamericano (Bustamante, 2016), todo ello sin perder de vista el papel que pueden tener en este escenario los artistas y la investigación en educación artística (Queiroz, 2015), e incluso lo que Reyes (2014) define como recreación, ya que «se hace imposible dejar vertida completamente una concepción particular de la recreación, y mucho menos si lo hacemos pensando en el contexto de la cultura, la pedagogía, e incluso, de la democracia y la política pública» (p. 90).

\section{Metodología}

Nuestro posicionamiento ante el panorama de las identidades del colectivo docente se basa en el respeto y en el deseo de conocerlo, estudiando aspectos de sus realidades a través de las opiniones que nos transmiten las propias mujeres maestras. La forma de conocer sus problemáticas supone acercarnos a ellas mediante la observación y el análisis en directo, utilizando las narrativas personales como fuente de información. Planteamos entrevistas semiestructuradas que son grabadas en video en sus respectivos centros educativos, preferentemente en los lugares donde ellas trabajan. La metodología que seguimos parte 
de los estudios de caso y se concreta en las narrativas personales. Por tanto, se trata de una metodología de corte cualitativo (Stake, 1999). Hemos realizado una aproximación basada en la praxis, elaborando un análisis desde la observación, vinculado la experiencia de manera específica a nuestras indagaciones sobre las identidades docentes desde la vertiente de la educación artística (Huerta, 2012). El proyecto Mujeres Maestras se concreta cuando unimos los esfuerzos de museos y centros educativos, implicando de forma participativa a educadoras, alumnado y familias en una iniciativa de corte social y cultural.

\section{3. ¿LA MAESTRA NACE O SE HACE?}

Durante tres décadas ejerciendo la docencia universitaria en la formación de futuros maestros, venimos comprobando que, entre el alumnado, destaca la población femenina. Se trata de mujeres que, en su inmensa mayoría, desean ser maestras que quieren dedicarse profesionalmente a la docencia. Lo dicen abiertamente, incluso, están orgullosas de plantearlo así, como algo que les atrae desde siempre. Si bien algunas de ellas iniciaron sus estudios de magisterio sin ser conscientes de su interés por este tipo de trabajo, lo cierto es que, durante sus ańos de formación, sienten como propio el hecho de haber asumido que su papel en la sociedad es el de ser maestras.

La inclinación por la docencia, de una persona que estudia para ello, ya habla mucho de una trayectoria vital, pero, sobre todo, nos remite a sus preferencias personales $y$, también, a su futuro profesional, puesto que ya ha decidido, desde que era joven, a qué quiere dedicarse. Deben tenerse en cuenta otros factores coyunturales, como la poca valoración social que suele darse al oficio de maestra (los salarios bajos), y por supuesto, especialmente cuando se trata del sector de maestras de infantil, el hecho de que, tradicionalmente, se ha emparentado a las mujeres con el papel o función de personas que atienden a los más pequeños, generando, así, un concepto que alude a una obsesión por equiparar a las maestras con lo que serían madres o cuidadoras.

La vocación docente va unida a otras características que se han entendido, tradicionalmente, en tanto que definitorias del profesorado: la paciencia, el diálogo, la responsabilidad, la generosidad, y, por supuesto, la implicación. En todos estos lugares comunes, ya convencionales y típicos, suele faltar el espíritu crítico y la reflexión sobre el papel de los docentes como auténticos intelectuales (Giroux, 1990). O, tal y como nos dice el propio Henry Giroux (2013), más recientemente, cuando afirma que «hay un creciente número de gente, especialmente jóvenes, que habita con mayor frecuencia zonas de dificultades, sufrimiento y exclusión terminal», frente a lo cual los educadores 
deberían abordar «cuestiones sociales importantes» y defender «la educación pública y superior como esferas públicas democráticas» (p. 13).

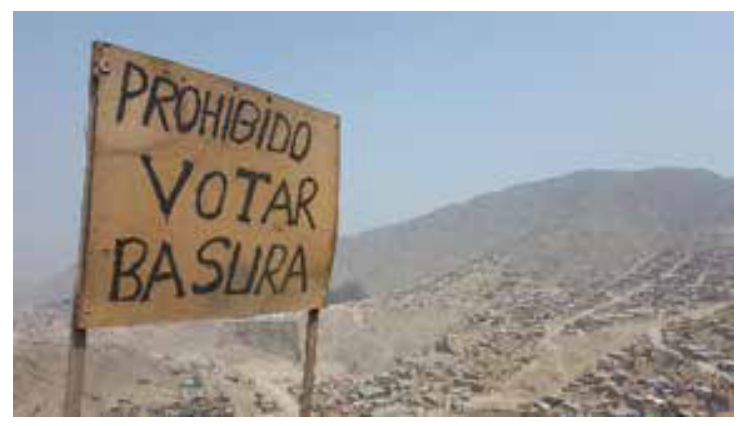

Figura 3. Foto tomada en Jicamarca (Lima), una de las zonas de aluvión humano, con población desplazada, donde se realizaron siete de las entrevistas a maestras.

Considerando que una mujer es ya maestra cuando realiza sus estudios de magisterio, desde el momento de su formación inicial, valoramos el periodo de preparación como un momento de responsabilidad y crecimiento profesional. Luego vendrán los ańos de experiencia en las aulas, pero una maestra en formación ya sabe, de antemano, en la mayoría de los casos, que quiere dedicarse a la docencia. Se trata de una carrera muy profesionalizada, donde el trato con personas (alumnado, compańeros, equipo directivo, padres) es la clave del desarrollo, en tanto que individuo social y trabajadora. En ocasiones el sentido vocacional se entrelaza con los aspectos familiares, ya que se trata de una profesión que, a veces, se hereda de padres y madres a hijas. Es frecuente escuchar que una maestra lo es porque en su familia hay alguien que le inspira mucho respeto y por eso decidió dedicarse a la docencia. Para cerciorarnos de la validez de estos territorios comunes, proponemos escuchar las opiniones de las docentes, en este caso, atendiendo a lo que nos dicen las maestras peruanas. En el presente trabajo, hemos optado por centrarnos en las declaraciones de una parte del conjunto de las entrevistadas en el país. Por un lado, destacamos los ejemplos que nos hablan desde un entorno muy desfavorecido, como es la zona de Jicamarca, y, por otro lado, las declaraciones de una serie de maestras de variada procedencia, con quienes pudimos contactar tanto en sus despachos como en los colegios de barrios más acomodados de Lima (San Isidro y Miraflores). Para designarlas, utilizaremos tres letras como acróstico, con el fin de mantener el anonimato de las participantes, excepto en el caso de la profesora jubilada Maribel Cormack Lynch. 
La maestra MPL trabaja en la Institución Educativa Parroquial de Acción Conjunta Corazón de Jesús, un centro ubicado en Jicamarca (San Juan de Lurigancho). Jicamarca define un territorio donde se explota el material de construcción para abastecer de arena y ladrillos a la capital. Los grandes huecos que ocasiona la extracción son utilizados como emplazamiento donde se instalan para vivir quienes huyen del conflicto y la pobreza en otros lugares mucho más peligrosos. Los miles de personas que habitan en este desierto no disponen ni de agua corriente ni tampoco de canalización de aguas residuales. Todo es muy precario para quienes viven en este amplio escenario de polvo y arena. Las maestras que trabajan allí proceden de otros barrios de Lima. Los trayectos son largos para venir hasta allí, lo cual supone un gran esfuerzo diario para llegar al puesto de trabajo. MPL es docente de secundaria en la especialidad de Lengua y Literatura. Dice que su vocación no era ser maestra, pero que «descubrió lo mágico en el proceso de enseñar». No fue aceptada para estudiar Derecho en la universidad debido a una serie de problemas burocráticos. Al preguntarle, su padre, qué le gustaría hacer, ella dijo que lo que realmente le gustaba era leer. Inició los estudios de Educación y en tercer curso, a raíz de una clase magistral sobre mitología griega, impartida por un profesor que le emocionó, optó por elegir Lengua y Literatura. Asegura que la pasión por su carrera la descubrió «en el proceso de ejercicio de la docencia». Le encanta trabajar con jóvenes, y ha estudiado una Maestría en Educación Superior. Se siente cómoda en el "Corazón de Jesús», donde ocupa el cargo de coordinadora pedagógica en el área de Comunicación. Es madre soltera y asume el papel que deben tener hoy en día las mujeres en tanto que trabajadoras con responsabilidades familiares (Alonso-Sanz, 2016).

A pesar de las dificultades reconoce que su motor es la ilusión de los muchachos, de sus estudiantes. Dice que ve en sus estudiantes a su hija, y que por eso se implica tanto, algo que en ocasiones le recriminan sus compañeras. Es consciente de los graves problemas por los que pasa su alumnado. MPL está muy sensibilizada por la problemática de la violencia contra las mujeres, aspecto que ha llevado a las aulas animando a sus alumnos para que tratasen la realidad de las familias disfuncionales. Esto se hizo mediante acciones artísticas, especialmente dibujos y grafitis, algo que motivó mucho al grupo. Entre las grandes pasiones de esta profesora, está la danza, especialmente las danzas folklóricas peruanas. También usa la música, un elemento lúdico que suele utilizar para animar los actos a los que asisten los padres. En ese sentido, MPL busca transmitir la pasión por el patrimonio, algo que según ella puede llegar a marcar el futuro del país, si se consigue generar un ambiente de respeto hacia el legado patrimonial (Huerta, 2015). 


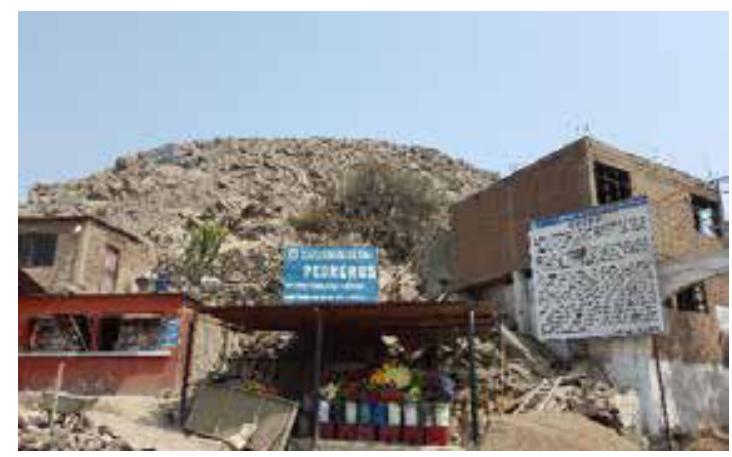

Figura 4. Al igual que ocurre en el resto del territorio peruano, en Jicamarca, se han encontrado numerosos restos arqueológicos precolombinos. La falta de medios impide que estos entornos patrimoniales sean recuperados y protegidos, como indica el cartel de la imagen.

Los trabajos sobre las identidades docentes, que surgen de las narrativas personales, suscitan un interés peculiar (Rifá, 2010), originando la búsqueda de referencias, partiendo de las voces de las propias maestras, algo que, posteriormente, analizamos y describimos, también, desde las componentes de la visualidad y de la cultura visual (Huerta, 2013). La perspectiva de las historias de vida es un campo de estudio que plantea desafíos, que no puede aplicarse como una fórmula a la intención del investigador y que se vincula al giro que la investigación en Humanidades y Ciencias Sociales tomó a partir de los años 70 (Hernández, Sancho y Rivas, 2011). En nuestra indagación, se ha tomado como caso de estudio a un conjunto de narrativas personales que se complementa con elementos artísticos, educativos, creativos y experimentales, puesto que se trata de un proyecto en el que se implican personas, centros educativos $y$, finalmente, museos, intercambiando actividades e intereses que introducen, en el proceso, las prácticas artísticas y la reflexión estética. Poder llevar a cabo la iniciativa supone mantener una relación estrecha con las maestras entrevistadas, lo cual nos permite conocer de primera mano sus opiniones (Huerta, 2010). En esta ocasión, el hecho de centrarnos en la vertiente vocacional tiene que ver con la selección de las entrevistadas.

La mayoría de las maestras peruanas con quienes nos hemos puesto en contacto trabajan para instituciones de índole religiosa. Al analizar la cuestión identitaria de estas maestras, surge, inmediatamente, dicho componente de adscripción vinculada al cariz católico de las instituciones donde trabajan. En cualquier caso, nos anima la posibilidad de acceder a sus problemáticas observando numerosos factores de suma importancia, como son las repercusiones 
emotivas o los sentimientos, elementos que tanta presencia adquieren en la vertiente cotidiana de la profesión docente (Huerta, 2014). Ser maestra no significa, solamente, nacer para ello. El esfuerzo que requiere la preparación durante la formación del profesorado supone incorporar, en cada narrativa personal, un elemento esencial, un factor que ejercerá como detonante de la profesión docente, a saber: la exigencia del trabajo bien hecho (Sennett, 2013). Las exigencias de actualización suponen un reto constante, ya que «el papel del docente es de gran responsabilidad, pues debe prepararse intensamente con el fin de apoyar el desarrollo de sus alumnos. No es tarea fácil, sobre todo, si la docencia no es la profesión de origen; sin embargo, cada maestro puede alcanzar los niveles necesarios para cumplir exitosamente su función» (Carro et al., 2016, p. 11).

\section{EJERCER COMO MAESTRA EN UN ENTORNO MUY DESFAVORECIDO}

Ser maestra en un entorno desfavorecido requiere mucha implicación. A las problemáticas laborales habituales del colectivo docente se suman elementos que dificultan el ejercicio profesional, como pueden ser la situación precaria de las familias del alumnado, o, incluso, el mal estado en que se encuentran las instalaciones donde se trabaja. Todos estos aspectos influyen decididamente en el desarrollo de la actividad educativa, lo cual acentúa factores perversos que afectan a otras cuestiones de rango personal, social y cultural. Así lo afirman González y Subaldo (2015) al evidenciar que «ser docente y educar con calidad en el momento actual supone un gran reto y una tarea que entraña gran dificultad», puesto que "vivimos en una sociedad que plantea constantes cambios, que generan problemas al sistema y a las instituciones educativas, cambios que producen incertidumbres y desgastes en el trabajo del profesorado» (p. 92). Todo ello se agrava cuando, además, el entorno en el que se trabaja es de suma pobreza económica. No obstante, cabe decir que, al oír a las maestras del centro de Jicamarca analizado, comprobamos que su opinión sobre los niños y las niñas del centro es de grandísimo respeto, ya que se trata de un alumnado muy motivado por mejorar su situación, algo que se suma al interés que demuestran las familias hacia la labor de las maestras.

$\mathrm{Al}$ acercar, al territorio de las artes, este conocimiento de una realidad concreta, será fundamental realizar la investigación teniendo en cuenta factores sociales, económicos, culturales y de género. En el caso Jicamarca, tuvimos la oportunidad de conocer en directo la situación que se vive en un territorio árido, en una zona de aluvión poblacional, un auténtico desierto donde subsisten familias que llegaron allí huyendo del terror vivido en las zonas agrícolas de la sierra durante las décadas del conflicto armado. La docente ZTC 


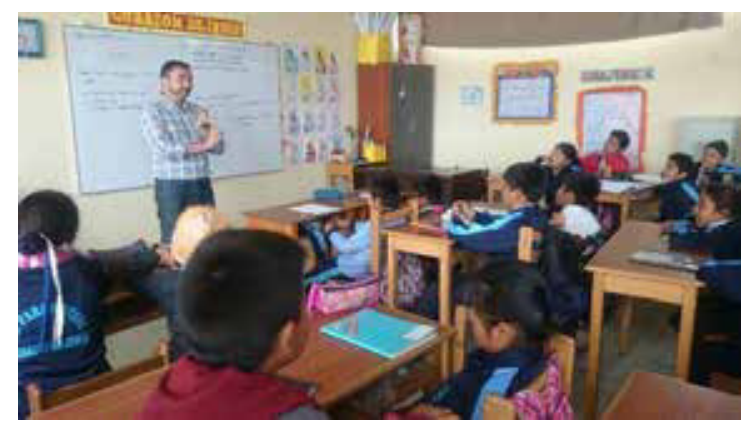

Figura 5. Conociendo al alumnado de Primaria de la Institución Educativa Parroquial de Acción Conjunta Corazón de Jesús, ubicado en Jicamarca. Foto: Mariella Tuccio.

atiende al alumnado de primer curso de primaria. Es maestra porque su madre le indujo a serlo, aunque ella, inicialmente, no quería, ya que en realidad deseaba ser enfermera. Su madre le decía insistentemente "postula, hija, postula». En el momento que empezó el contacto con los nińos, comprobó que el oficio de docente sería su verdadera carrera. Trabajó en diferentes colegios hasta que llegó al Corazón de Jesús. Allí lleva cinco años consecutivos y se encuentra muy a gusto, porque valora positivamente que el trato al profesorado sea igualitario y equitativo por parte de la dirección. Considera fundamental «hablar con los padres, porque es al conversar con ellos cuando entiendes realmente a tus niños» (ella usa la expresión «tus niños»).

Le gusta "dedicarse a los niños que tienen problemas, a los que son rebeldes, para animarles a estudiar, para que dejen la calle». En los casos más difíciles, o de mala conducta, destaca el inmenso poder que adquiere «dar conversación y dar cariño", además de "darles responsabilidades a quienes se sienten menos valorados». A este respecto, recogemos de Giroux (2013) la importancia que concede el autor al factor responsabilidad, cuando asegura que «la educación como forma de esperanza educada no implica, simplemente, fomentar una conciencia crítica sino, además, como ha dicho Zygmunt Bauman, enseñar a los estudiantes a asumir la responsabilidad de sus responsabilidades, ya sean personales, políticas o globales», añadiendo que «se debe concienciar a los estudiantes acerca de las fuerzas ideológicas y estructurales que promueven el sufrimiento humano innecesario y, a la vez, hay que reconocer que se necesita más que concienciación para resolver estas cuestiones» (p. 17).

Retomamos las palabras de la maestra ZTC, quien se siente satisfecha de haber logrado que alumnos que habían abandonado el centro hayan vuelto para terminar sus estudios, lo cual «supone para ellos una segunda oportu- 
nidad». Se siente «realizada como maestra». Insiste en la necesidad de "hacerles sentir importantes, ocuparse de ellos, atenderles, escucharles». Propone como meta «establecer con ellos un compromiso que se base en el respeto y la confianza». Frente al «sacrificio que supone tener que levantarse temprano, viajar para llegar al trabajo, tener que atender las tareas de la casa cuando vuelves», nos dice que se siente «feliz al entrar en el aula, ya que es donde mejor se encuentra, donde está bien». ZTC da "gracias a Dios por ser madre de dos niños», a quienes transmite «el respeto que deben tener hacia sus maestras».

\section{UNA MAESTRA DE REFERENCIA CON UNA DILATADA Y PODEROSA CARRERA DOCENTE}

Hemos tenido la oportunidad de entrevistar a Maribel Cormack Lynch, maestra de formación inicial, galardonada recientemente con las Palmas Académicas en reconocimiento a su trayectoria profesional. Se formó con la fundadora de los Jardines de Infancia Emilia Barcia Boniffatti, con quien asegura haber aprendido lo que significa educar a los más pequeños, es decir, «atender a la formación integral del niño». Fue directora de centro educativo en la Residencial San Felipe, donde tuvo la «oportunidad de trabajar estrechamente con la comunidad». Trabajó "como formadora de formadores en el Instituto Pedagógico», y también como especialista en el Ministerio de Educación, lo cual le permitió recorrer todo el Perú en el tiempo de la Reforma Educativa, y conocer «distintos lugares, distintas costumbres, distintas formas de expresarse». Tras retirarse se ha centrado en las consultorías, especialmente en aspectos referidos a las transiciones, la educación integral, o el estado del arte en la educación inicial. Sigue dictando cursos dirigidos a maestros y últimamente colabora con la Red Hemisférica de Parlamentarios por la Primera Infancia, motivándoles para que «en su labor legislativa tengan presente las necesidades de la primera infancia. Destaca su experiencia en pequeñas poblaciones en la frontera con Ecuador, donde pudo comprobar «la eficacia de las tareas artísticas que comparten niños y padres, haciendo cerámica, interpretando música y bailes, conociendo y conservando los aspectos patrimoniales de los que son herederos».

Dice Maribel Cormack que «debemos seguir trabajando para que todos los niños del Perú tengan acceso al nivel inicial, para lograr la igualdad de oportunidades». Cormack sigue luchando por extender el derecho a la educación infantil a toda la población peruana, y por ampliar el papel de las artes en la formación de los más pequeños. En ese sentido recuperamos, aquí, las palabras de Giroux (2013) cuando asegura que «la pedagogía es una práctica moral y política que siempre se halla implícita en las relaciones de poder porque 

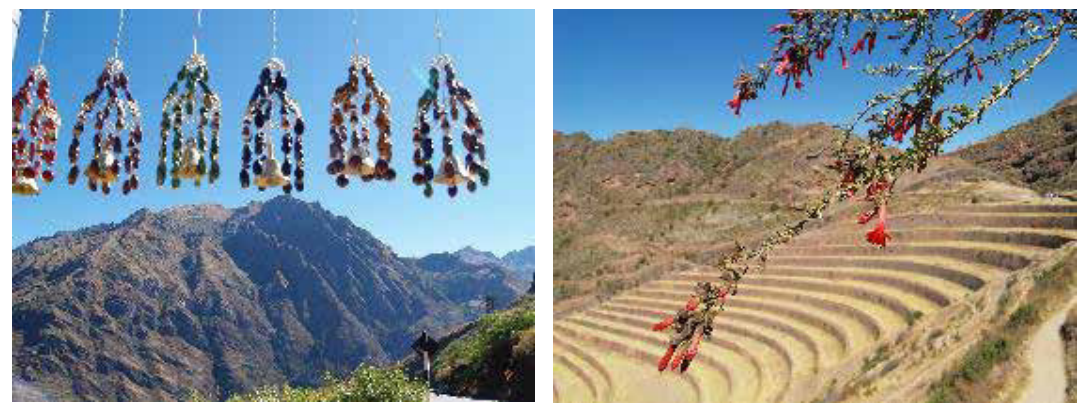

Figuras 6 y 7. La riqueza patrimonial y cultural del Perú es riquísima y diversa, unida al valor de los espacios naturales. Las maestras reivindican el reconocimiento de esta realidad amplia y generosa. Imágenes tomadas en Pisac.

ofrece versiones y visiones particulares de la vida cívica, la comunidad, el futuro, y el modo en que podríamos construir representaciones de nosotros mismos, de los otros, y de nuestro medio ambiente físico y social» (p. 15).

El ejemplo de Maribel Cormack nos aporta un caso muy solvente de lo que supone implicarse a nivel institucional en la reivindicación del papel de las maestras. Esta mujer nos transmite un gran deseo de continuar luchando por la educación infantil, ya que todavía queda mucho por hacer. Al revisar su caso comprobamos que «las experiencias satisfactorias conducen al desarrollo personal», de lo contrario "las insatisfactorias llevan al deterioro personal y profesional, al sentimiento de frustración e impotencia frente a las dificultades, a la desmotivación y al desinterés frente a las necesidades de los alumnos, y, finalmente, pueden llegar al desequilibrio emocional, al desgaste profesional o burnout y a la pérdida del sentido de la vida» (González y Subaldo, 2015, p. 97).

\section{Elaborar UN Discurso aRTístico QUE REIVINDICA a las docentes del Perú}

Para llevar a cabo la serie de pinturas que representará a las maestras del Perú, se necesita conocer, personalmente, a estas docentes. Del mismo modo que el artista plasmará en sus pinturas a cada mujer, también el alumnado interpretará con sus dibujos a sus maestras. Todo este material gráfico formó parte de la exposición «Mujeres Maestras del Perú» en agosto de 2017 en Lima. A las miradas del artista y del alumnado se une la mirada de las propias maestras, quienes son escuchadas a través de los videos que han sido grabados durante las entrevistas. El trabajo de recogida de información se realizó, básicamente, durante el último trimestre de 2016, primero conociendo a las maestras y 
registrando en video las entrevistas, después, transcribiendo sus comentarios, destacando algunas opiniones, y realizando, en el taller, la serie de pinturas que las representan. En las entrevistas, se planteaban cuestiones abiertas, a partir de ideas como el motivo por el cual decidieron ser maestras, las temáticas que les preocupan, tanto a nivel personal como a nivel laboral, así como de qué modo concilian su vida familiar con las tareas de la enseñanza.

CNL es profesora en la Asociación Educativa Colegio Caritas Graciosas, un centro privado especializado en educación inicial del distrito de Miraflores (Lima). Lleva más de 35 ańos ejerciendo como maestra. Ella menciona que, desde chiquita, jugaba "a ser la profesora en el colegio». Nos confiesa, además, que «han sido algunas maestras que he tenido quienes reafirmaron mi deseo de ser docente». "Los niños me han fascinado desde siempre», dice CNL, y hace tres décadas fundó el centro en el que trabaja, en un «barrio bastante acomodado de Lima». En ello influyó mucho su «curiosidad por ver cómo aprendían los niños»; de hecho, sigue «buscando ideas y propuestas innovadoras para mejorar en sus prácticas de enseñanza». Está a favor de «encontrar una identidad peruana, a partir de la equidad», de manera que lo que se hace en su centro "pueda estar al alcance de cualquier nińo peruano». "El rol de la profesora es importantísimo», asegura CNL, ya que "te puedes enamorar de esta profesión».

Mientras ella habla, escuchamos constantemente a nińos gritando y jugando en los distintos espacios del centro, algo que para CNL resulta esencial, que disfruten participando. "Los nińos aprenden a partir de lo que hay a su alrededor, y, si aquí tienen un parque, en la selva disponen de árboles, de canoas; cualquier elemento que les atraiga puede servirnos para transformarlo en objeto educativo», nos dice CNL. Ella utiliza habitualmente las canciones, acompanándolas con su guitarra, y cree que «cada maestra tiene su propia forma de aportar un elemento artístico a su ruta, un camino en el que implicar a su alumnado a través del aprendizaje». Está fomentando programas educativos y sociales para compartir con centros de otras zonas menos favorecidas del Perú.

En cada entrevista, y, sobre todo, con el encuentro con cada maestra, se recoge la suficiente información para poder realizar posteriormente la pintura que la representa, siempre a partir de su nombre. Al presentar las pinturas en el museo convertimos a las maestras en protagonistas del discurso expositivo. Sus narrativas personales constituyen la base de todo el proceso. Tanto los colores y los grafismos como las formas de representarlas acaban formando parte de un entramado capaz de gestar, desde la cultura visual, una nueva mirada hacia las docentes, y, también, una nueva percepción de las maestras, potenciando así una mayor visibilidad del colectivo, utilizando, para ello, argumentos sociales, culturales, políticos, económicos y artísticos. 

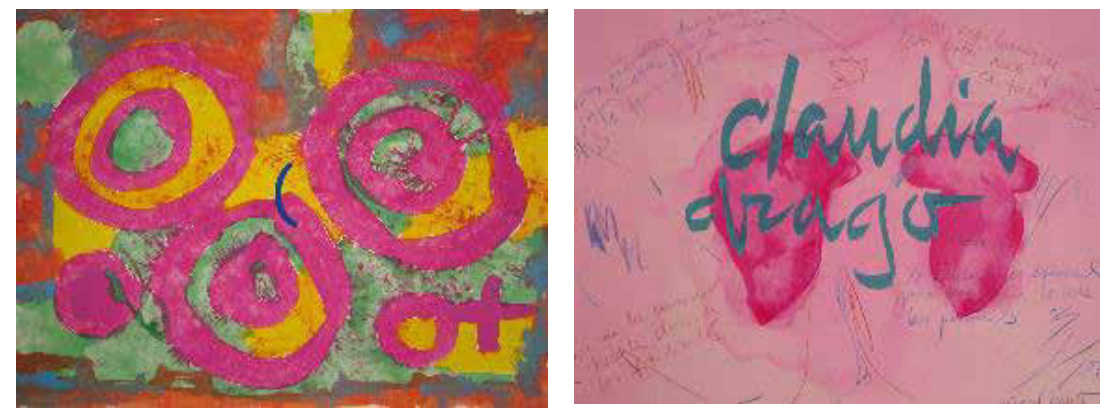

Figuras 8 y 9. Letra $\mathrm{C}$ del Alfabeto de las Maestras de Europa, y pintura dedicada a Claudia Drago de la serie Mujeres Maestras de Chile.

\section{Maestras de todas las EDADES EN UN MONTAJE QUE UnE ARTE Y EDUCACIÓN}

Durante la gestación del proyecto expositivo se van decidiendo aspectos que influirán en su presentación. Organizamos las diferentes partes de la exposición que se ubicarán posteriormente en las salas del museo, y resolvimos, al mismo tiempo, todas las cuestiones que afectarán al montaje. En las prácticas educativas artísticas suele predominar la parte procedimental, aquello que se produce en el proceso de taller. Para nosotros también resulta clave que la reflexión se extienda a una faceta más conceptual, considerando la vertiente teórica desde la propia realidad artística. En Mujeres Maestras combinamos ambos aspectos, facilitando una reflexión compuesta por ideas, sentimientos, imágenes y textos, generando así acción y reflexión teórica. Utilizamos para ello procesos de investigación basada en las artes (Arts Based Research), e implicamos a los estamentos y colectivos de cada centro, consiguiendo así unir esfuerzos y logrando una mayor integración entre las partes.

CSF ha trabajado en distintos niveles educativos y ahora es profesora de docentes en la universidad. Estudió educación inicial, y, además de ejercer la docencia, también estuvo en otros países estudiando idiomas, por lo que obtuvo una maestría en educación y otra en estudios latinoamericanos. "Me interesa especialmente la animación a la lectura en niños de inicial y primaria», nos dice. «En Perú no he tenido la oportunidad de disfrutar de una biblioteca en la cual poder leer aquello que realmente me gustase»; por ello, plantea que se debería «acercar a los nińos la lectura desde muy temprano, transmitiendo la pasión por los libros». «He trabajado en ambientes extracurriculares con bibliotecarios, psicólogos, pedagogos, de quienes he aprendido mucho», $\mathrm{y}$ «soy 
maestra porque tuve malas experiencias durante la escuela primaria, lo cual me impulsó a formarme como docente para evitar que se repitiesen situaciones que me tocó sufrir».

El contraste lo encuentra CSF en el hecho de que sus padres «distaban mucho de lo que hacían las maestras que yo tuve», y resume diciendo que "conviene evitar que algunas maestras ahoguen la creatividad de los niños». También una experiencia negativa puede conseguir que desatemos nuestras urgencias creativas, tal y como demuestra el relato de CSF. Pero lo importante será que tengamos en algún momento la posibilidad de ampliar nuestro escenario expresivo. Tal y como afirma Luz Marina Hermoza (2015) «la experiencia estética es el resultado del encuentro entre el sujeto en su biografía emocional, el objeto estético y el marco de las circunstancias donde se construye los significados culturales» (p. 54).

Con la edad cambia y se modifica el aspecto de las personas, pero nuestro nombre perdura afirmándose como elemento gráfico de nuestra identidad. Es por ello que, en los retratos de las maestras, tendemos a utilizar sus nombres, retratándolas con este símbolo gráfico que las define desde el alfabeto. Y, mientras el artista moldea la singularidad de cada maestra, partiendo de la composición tipográfica, las manos de los niños y las niñas interpretan a sus maestras a partir de sus composiciones plásticas en en las cuales queda reflejado el enorme cariño que manifiestan por estas profesionales de la educación. Los retratos de las maestras son un mensaje con el que deseamos transmitir nuestro respeto y admiración por el esfuerzo de estas mujeres, trabajadoras de la cultura, maestras y profesoras.

En las exposiciones de Mujeres Maestras se unen los relatos vitales de las docentes con los experimentos gráficos del alumnado (Maeso, 2008), de modo que se cruzan sus miradas, sus interpretaciones y sus reflejos en el marco humano y profesional de la propia exposición. Se trata de un homenaje con vocación reivindicativa. Está en la línea de las exposiciones donde domina la vertiente pedagógica (Huerta, Alderoqui y Linares, 2014). Tal y como afirma LZM, una de las maestras entrevistadas: «A mí siempre me gustó el arte, pero desde pequeña siempre fui la tía preferida para cuidar a todos los bebitos de la familia», con el tiempo "accedí a una institución en la que preparaban a profesores para ejercer la educación artística, donde me metí curioseando, y, finalmente, entendí que mi pasión era educar en artes». LZM, docente en el Colegio Caritas Graciosas, de Miraflores, asegura que "enseñar es una emoción, más allá de los conocimientos que se transmiten o se adquieren». Se decantó por la educación inicial a raíz de una experiencia formativa, y lleva casi treinta años disfrutando de este trabajo que le emociona. 


\section{Conclusiones}

El Proyecto Mujeres Maestras transita por los territorios de los entornos formales e informales, uniendo la capacidad de las escuelas y los museos en una experiencia creativa y participativa. Acercamos ambas instituciones para reforzar el mensaje de nuestra propuesta: homenajear y visibilizar al colectivo de las maestras. Al representar a las docentes también generamos una nueva imagen que las define. Ya no son solamente profesionales de la enseńanza, son figuras emblemáticas a quienes se les reconoce su mérito, su valentía y su dedicación. Más allá de la posible vocación que lleva a estas mujeres a dedicarse a la docencia, lo cierto es que, con su labor un alto grado de concienciación social, demuestran lo que las convierte en verdaderos ejemplos de trabajo bien hecho. El oficio de maestra responde a parámetros de humildad y anonimato, lo cual no evita que nos sintamos orgullosos de sus logros.

Nuestra investigación parte de la educación artística para integrar el trabajo colaborativo y rendir un caluroso homenaje a este colectivo tan numeroso, pero tan poco visible. Celebramos la colaboración de los museos y de las entidades que participan, ya que, para llevar a cabo el proyecto Mujeres Maestras, es necesario integrar el esfuerzo de los museos, las salas de arte y los centros educativos, lo cual supone involucrar de forma participativa a educadoras, alumnado y familias en una iniciativa de marcado cariz cultural. Fomentamos estas acciones a través de un ambiente lúdico y entusiasta, en el que domina la lucha por los derechos y la reflexión sobre el papel de las maestras en los entornos educativos. Finalmente, denunciamos la precaria situación en la que viven muchas maestras, debido a la poca remuneración de su trabajo, teniendo en cuenta su dedicación, su esfuerzo y la constante preparación que se les demanda.

\section{REFERENCIAS BIBLIOGRÁFICAS}

Alonso-Sanz, A. (2016). Conciliación de la vida estudiantil, familiar y laboral de una madre universitaria. Revista de Antropología Experimental, 16, 223233. https://doi.org/10.17561/rae.v0i16.2516

Bustamante, B. (2016). Aproximación a una re-conceptualización de la educación artística en la sociedad del conocimiento en Colombia'. Gearte, 3(2), 151161. https://doi.org/10.22456/2357-9854.64798

Carro, A. et al. (2016). Formación profesional y competencias docentes en el estado de Tlaxcala'. Educación, XXV(49), 7-28.

Giroux, H. (1990). Los profesores como intelectuales. Barcelona: Paidós.

Giroux, H. (2013). La pedagogía crítica en tiempos oscuros. Praxis Educativa, $X V I I(2), 13-26$. 
González, J. y Subaldo, L. (2015). Opiniones sobre el desempe-o docente y sus repercusiones en la satisfacción profesional y personal de los profesores. Educación, XXIV(47), 90-114.

Hermoza, L. M. (2015). La evaluación formativa-colaborativa para la construcción de aprendizaje en los alumnos de arte y diseño. Educación, XXIV(46), 47-72.

Hernández, F., Sancho, J. M. y Rivas, J. I. (coords.) (2011). Historias de vida en educación: Biografías en contexto. Barcelona: Universidad de Barcelona.

Huerta, R. (2009). Maestras y museos. Matrimonio de conveniencia. Revista Educación y Pedagogía, 55, 89-103.

Huerta, R. (2010). Un proyecto de investigación en educación artística: aspectos identitarios de las maestras chilenas. Pulso Revista de Educación, 33, 31-59.

Huerta, R. (2012). Mujeres Maestras. Identidades docentes en Iberoamérica. Barcelona: Graó.

Huerta, R. (2013). La identidad como geografía liminar. Nuevas ideas para la educación en artes visuales. Aula de Innovación Educativa, 220, 12-17.

Huerta, R. (2014). La educación artística como motor de cambio social. Cuadernos de Pedagogía, 449, 46-50.

Huerta, R. (2015). La ciudad y sus docentes. Miradas urbanas desde las artes y la educación. Barcelona: UOC.

Huerta, R. (2016). Transeducar. Arte, docencia y derechos lgtb. Madrid-Barcelona: Egales.

Huerta, R., Alderoqui, S. y Linares, M. C. (2014). Tango y paella. Porteńas y valencianos en el comisariado de exposiciones con acento educativo. Educación, 45, 125-142.

Maeso, A. (2008). Influencia de los ámbitos familiar, educacional y mediático en la adopción de identidades por los ni-os y las niñas a través de sus dibujos. Arte, Individuo y Sociedad, 20, 107-128.

Queiroz, J. P. (2015). Os novos discursos sobre arte, agora escritos pelos artistas. Gearte, 2(2), 134-146.

Reyes, A. (2014). Cultura de la recreación, democracia y conciencia política. Educación, XXIII(44), 88-111.

Rifá, M. (2010). Narrativas autobiográficas en la investigación educativa basada en las artes y en el currículum de formación del profesorado. En Eça Agra et al., Desafios da educaçao artistica em contextos ibero-americanos (pp. 36-47). Porto: APECV.

Sennett, R. (2013). El artesano. Barcelona: Anagrama.

Stake, R. E. (1999). Investigación con estudio de casos. Madrid: Morata. 